\title{
Evaluation of the Sensitivity of the Updated RegCM4 Model to Physics Parameterizations over the Mediterranean Region: Precipitation and Temperature Simulations ${ }^{\dagger}$
}

\author{
Kondylia Velikou* and Konstantia Tolika \\ Department of Meteorology and Climatology, School of Geology, Faculty of Sciences, \\ Aristotle University of Thessaloniki, Thessaloniki 54124, Greece; diatol@geo.auth.gr \\ * Correspondence: kvelikou@geo.auth.gr \\ + Presented at the 2nd International Electronic Conference on Atmospheric Sciences, 16-31 July 2017; \\ Available online: http://sciforum.net/conference/ecas2017.
}

Published: 17 July 2017

\begin{abstract}
The main purpose of this research is to study the sensitivity of regional climate model RegCM4.4.5.1 to the different physics parameterization schemes in the Mediterranean region. The spatial resolution of the model is $25 \times 25 \mathrm{~km}$. Different ERA-Interim-driven simulations were performed with changes in the model's configurations for the time period 1981-1990. The different simulated data of temperature and precipitation were processed seasonally and the differences between the simulations were examined. The statistical significance of the differences is calculated with Student's t-test. Aiming a more detailed evaluation of the changes that occur, a division of the area of study into five sub-regions was performed according to the common EURO-CORDEX analysis domain and the Taylor diagrams for the examined parameters were calculated. From the analysis of the results it was found that Grell, Mixed, UW-PBL and CORINE simulations present a cold bias, while in BATS1e run temperature is increased. Additionally, Grell, Mixed and UW-PBL simulations present a decrease of precipitation except for winter, where in Grell simulations total precipitation is increased. In BATS1e run an increase of the parameter is detected. Finally, changes in land cover led to a reduction of the parameter during winter and an increase in summer.
\end{abstract}

Keywords: RegCM4; physics parameterization schemes; precipitation; temperature

\section{Introduction}

Temperature and precipitation are two parameters that are affected by a great number of factors, such as the interaction between the ocean and the atmosphere, which lead to the release of heat and the emission of water that returns on land as precipitation [1], changes in boundary layer that can cause the heating or cooling of the ground, as updrafts and downdrafts are related with an increase and decrease of temperature respectively [2], changes in convection processes that can lead to excessive or reduced precipitation, and also changes in evaporation and transpiration rates, which are linked to changes in landuse types and can cause alterations in temperature and precipitation [3]. In a regional climate model, these factors are represented by certain physics parameterization schemes. A great effort is being made by the scientific community in order to examine the sensitivity of regional climate models to specific parameterizations. According to [4], precipitation in centraleastern Europe is enhanced when using MIT-Emanuel scheme, due to the more convection that occurs in this scheme in contrast to Grell scheme. Grell scheme also presents a cold bias, which was detected in the Caribbean region [5]. The authors also examined the modifications that occur when changing the model's ocean flux scheme and concluded to a reduction of the cold bias in BATS1e 
scheme and an enhancement of convective precipitation. In terms of planetary boundary layer configurations, UW-PBL scheme appears to be more advantageous in regions with warm and dry biases [6]. Changes in land cover data affects regional climate models and as a result atmospheric circulation and seasonal and interannual variability are influenced [7].

\section{Experiments}

\subsection{Data}

The main purpose of this study is to examine the sensitivity of regional climate models to the different physics parameterization configurations and the modifications that occur in precipitation and temperature due to changes in the different parameterization schemes. For this reason, we used total and convective precipitation data, as well as near surface minimum and maximum temperature data derived from RegCM4 (version RegCM4.4.5.1), a regional climate model that was originally developed at the National Center for Atmospheric Research (NCAR). It is a hydrostatic, compressible with sigma-p vertical coordinate model [8-10]. The dynamical core of RegCM4 is similar to that of the hydrostatic version of the NCAR-PSU Mesoscale Model version 5 (MM5) [11]. The model's spatial resolution is $25 \times 25 \mathrm{~km}$. The domain of study covers the Mediterranean region (Figure 1). For a more detailed study of the physical parameterizations of the model, a division of the area into five subregions (Table 1) according to the common EURO-CORDEX analysis domain [12] was performed (Figure 1).
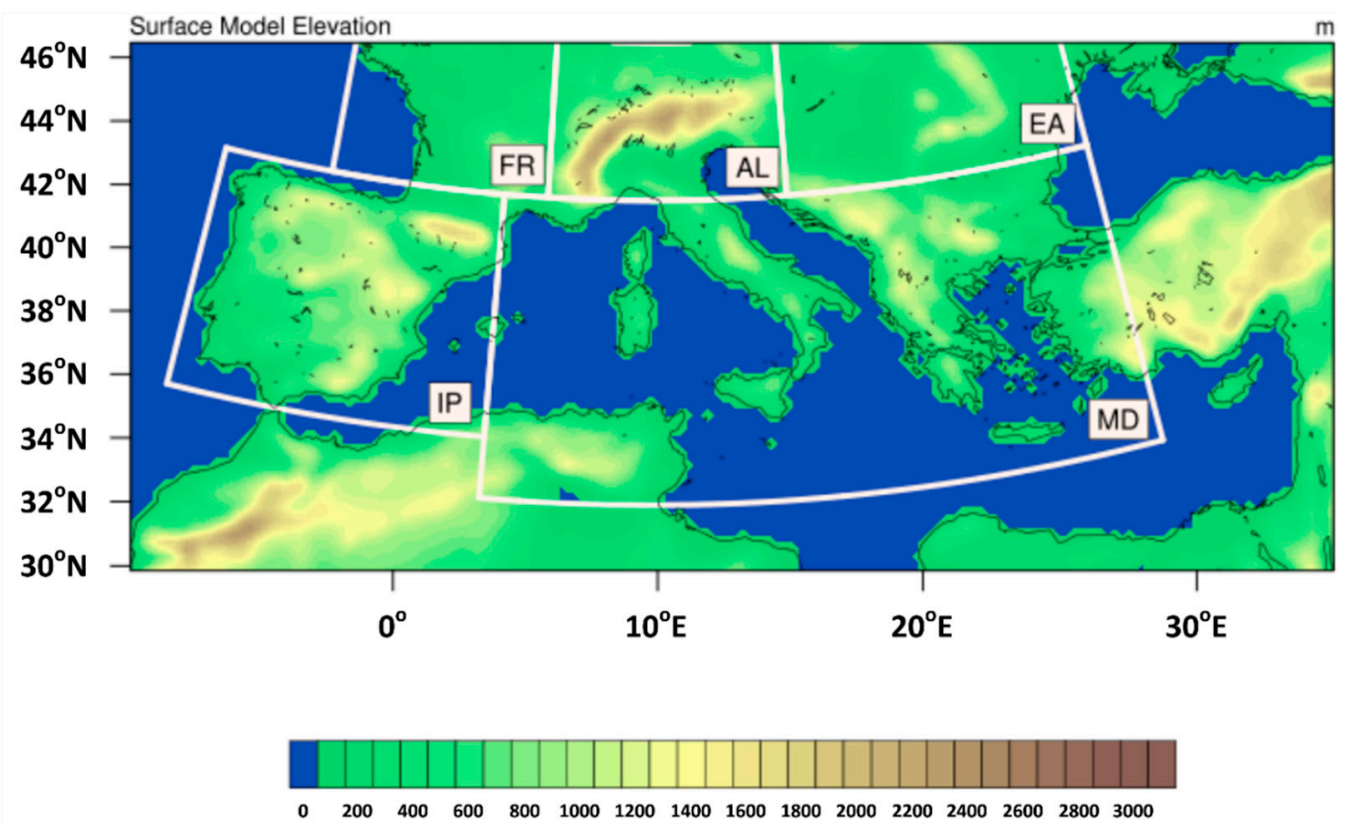

Figure 1. Topography $(\mathrm{m})$ of the domain of study. The boxes represent the division of the area into five sub-regions according to the common EURO-CORDEX analysis domain.

Table 1. The five sub-regions and their area of expansion.

\begin{tabular}{cl}
\hline Abbreviation & \multicolumn{1}{c}{ Area } \\
\hline AL & The Alps and the surrounding area \\
EA & The part of Eastern Europe \\
FR & The wider France region \\
IP & The Iberian Peninsula \\
MD & The greatest part of the Mediterranean Sea, Italy, Greece, \\
& the Balkans and southwestern Turkey \\
\hline
\end{tabular}




\subsection{Methodology}

Different simulations were performed with changes in the model's physics parameterizations for the period 1981-1990. More specifically, for the first simulation, the initial configurations of the model were used and this was characterized as "default" simulation (Table 2). Subsequently, we performed three simulations with changes in cumulus convection scheme and its closure assumptions from MIT-Emanuel [13] to (1) Grell [14] with Arakawa-Schubert closure assumption [15] (GAS); (2) Grell with Fritsch-Chappell closure assumption [16,17] (GFC) and (3) Grell with FritschChappell closure assumption over land and MIT-Emanuel over ocean (Mixed), one simulation with changes in planetary boundary layer scheme from Holtslag PBL [18] to UW PBL [19,20] (UW-PBL), one simulation with changes in ocean flux scheme from Zeng et al. [21] to BATS1e Monin-Obukhov [10] (BATS1e) and one simulation with changes in the model's land cover and land use data, where land cover data from CORINE 2000 Land Cover Project [22,23] were implemented in the model's BATS Land Surface Model [24,25] (CORINE) (Figure 2). All simulations are ERA-Interim-driven for sea surface temperature (SST) and initial and boundary conditions (ICBC).

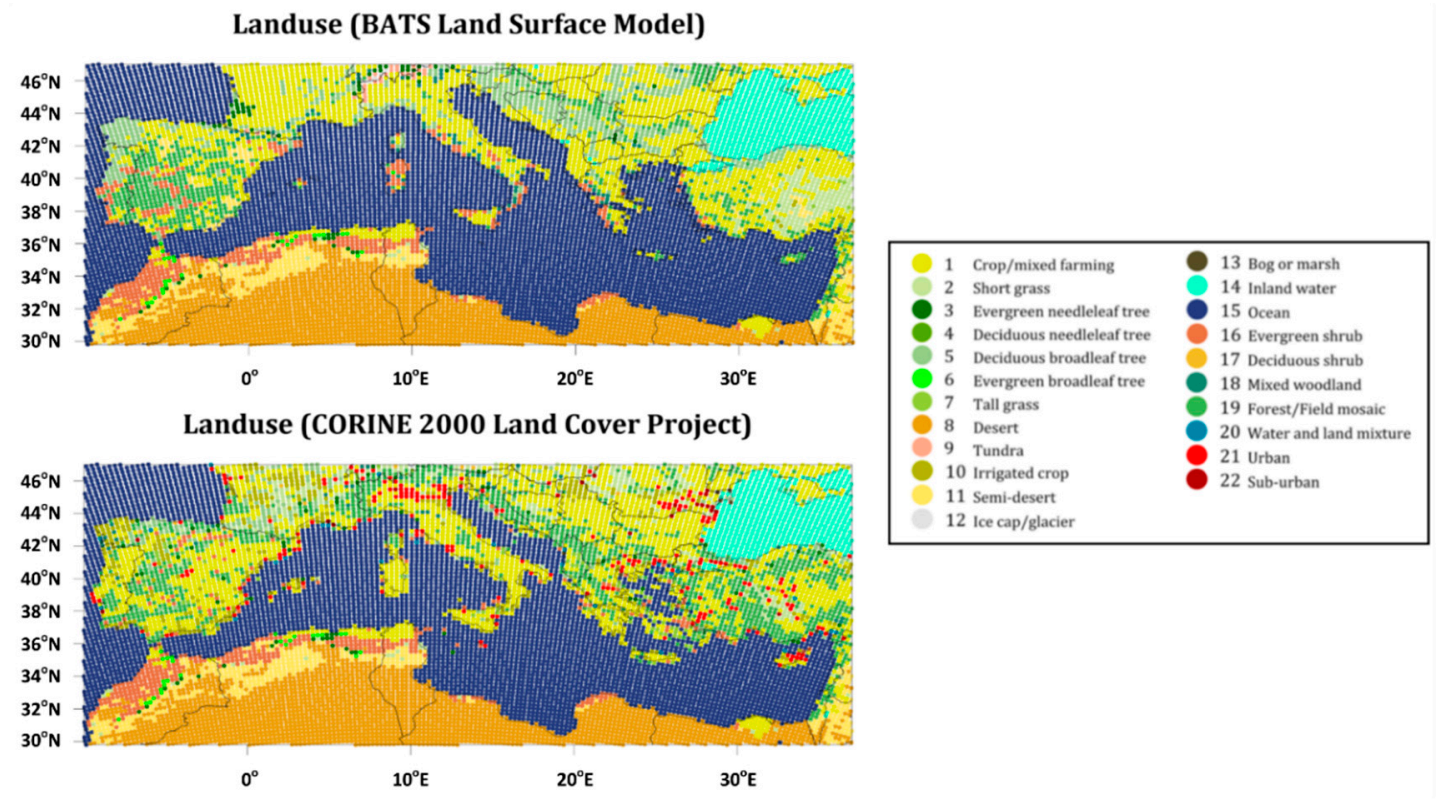

Figure 2. Land cover of BATS Land Surface Model and CORINE 2000 Land Cover Project.

Table 2. The initial configurations of the model used as "Default" simulation.

\begin{tabular}{cc}
\hline & Default \\
\hline Driving Field & ERAINT \\
Cumulus Scheme & MIT-Emanuel \\
Convective Closure Scheme & - \\
Planetary Boundary Layer Scheme & Holtslag PBL \\
Ocean Flux Scheme & Zeng et al. \\
Land Surface Model & BATS \\
\hline
\end{tabular}

In order to evaluate the changes in the model's physics parameterizations, the differences between the runs with the changes and the "default" run were calculated, mapped and compared. The statistical significance of these differences was found with the Student's $t$-test [26]. Subsequently, the Taylor diagrams of the examined parameters were computed for each sub-region [26,27] in order to examine the simulations in terms of correlation, RMS difference and standard deviation. As reference data in the Taylor diagrams the "default" run was used. All processing of the different simulated data was performed on a seasonal basis. 


\section{Results}

\subsection{Precipitation ( $\mathrm{mm}$ )}

Regarding precipitation, the main parameterization that is expected to influence both total and convective precipitation is cumulus convection scheme. During winter (Figure 3), GAS and GFC run are characterized by an increase of total precipitation in continental areas, with the most statistically significant increase being detected in the windward side of mountainous areas. On the contrary, convective precipitation in GAS and GFC run presents a significant decrease, which is more intense in maritime areas. In Mixed simulation, there are no significant changes in total precipitation, but in convective precipitation a decrease of the parameter in continental areas is evident. Both total and convective precipitation present a significant increase in BATS1e simulation, while in the case of UWPBL run a small but significant decrease is evident in maritime areas (mainly in convective precipitation). Finally, changes in land cover lead to a decrease of precipitation in coastal areas, which is significant only in the case of convective precipitation. The aforementioned findings are in agreement with the Taylor diagrams for each sub-region. BATS1e simulation presents the closest agreement with the reference field for both total (Figure 4) and convective (Figure 5) precipitation in all sub-regions. Mixed scheme presents a very good performance in most cases for total precipitation. Additionally, the increase of total precipitation in GAS and GFC simulations in mountainous ranges and the reduction of convective precipitation in these two simulations are also evident in Taylor diagrams. In convective precipitation the variations are much larger than the reference field.

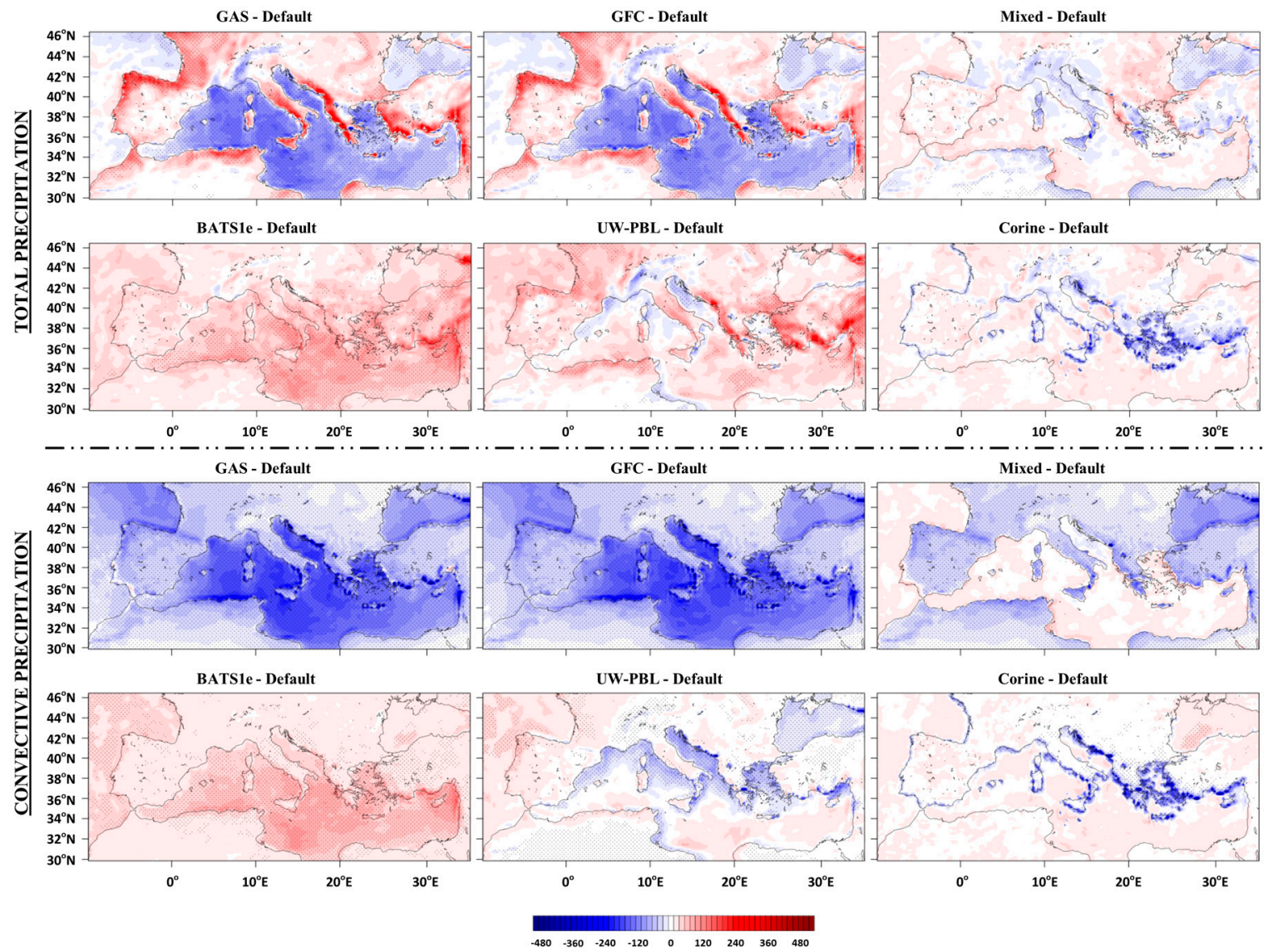

Figure 3. Differences in total and convective precipitation from the default simulation for the performed simulations during winter. The statistical significance of the differences in the maps is represented by the dotted areas. 
WINTER
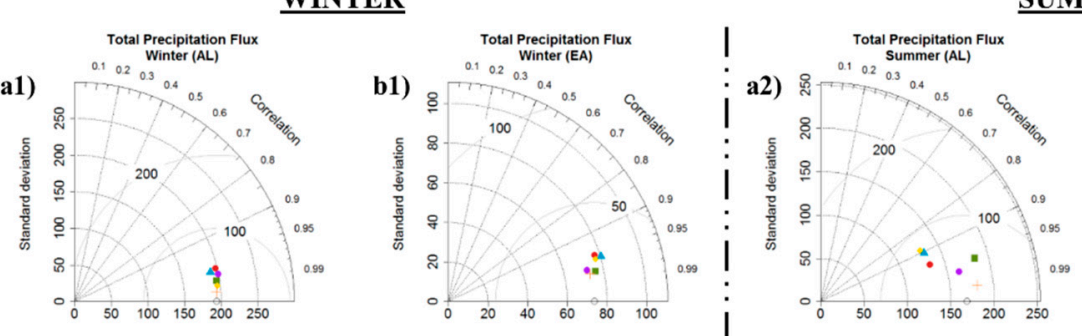

SUMMER
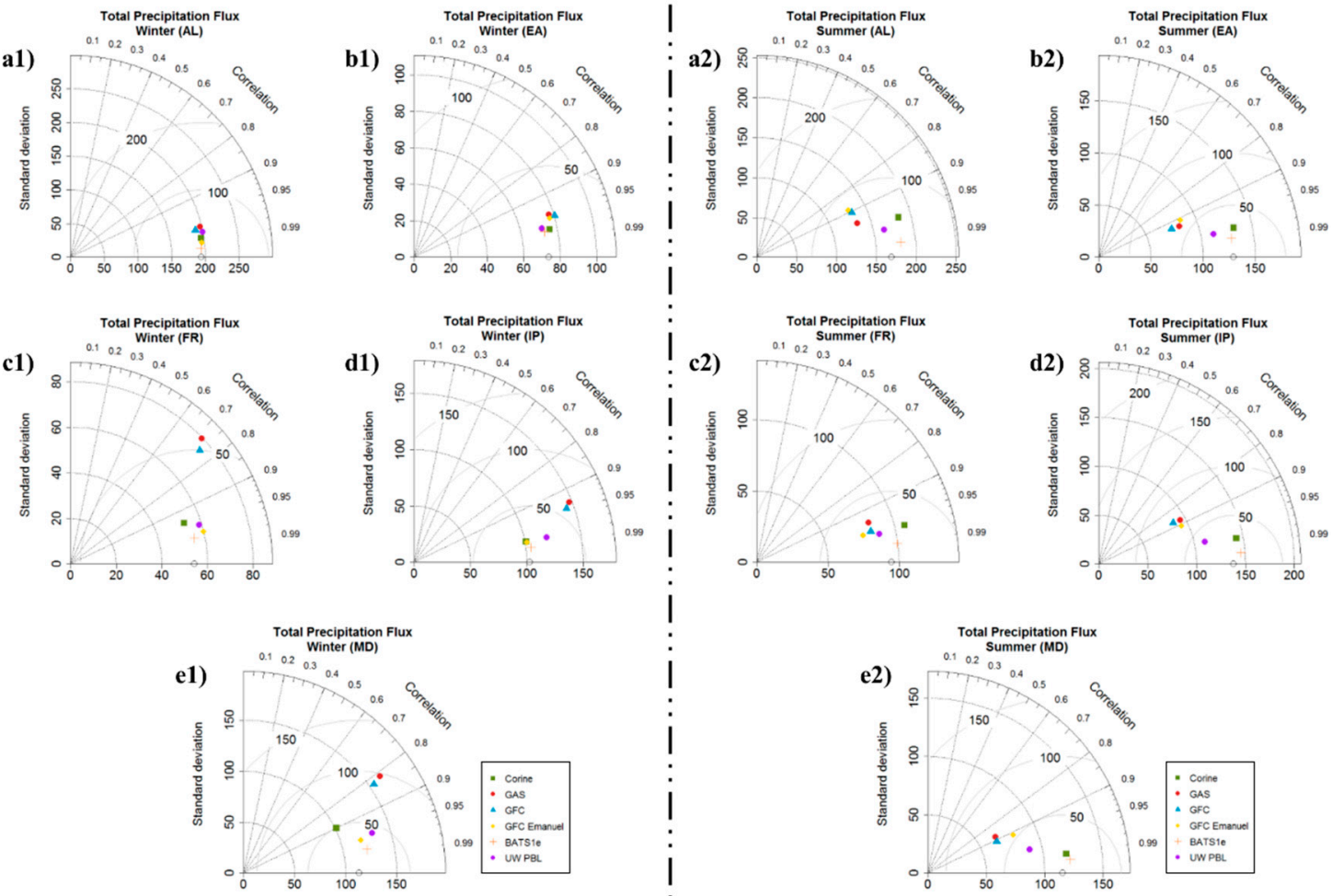

Figure 4. Taylor diagrams exploring the model's performance for total precipitation over the five subregions $(a \rightarrow A L, b \rightarrow E A, c \rightarrow F R, d \rightarrow I P, e \rightarrow M D)$ during winter and summer. The markers in Taylor diagrams represent the different simulations. The default simulation is being used as reference field.

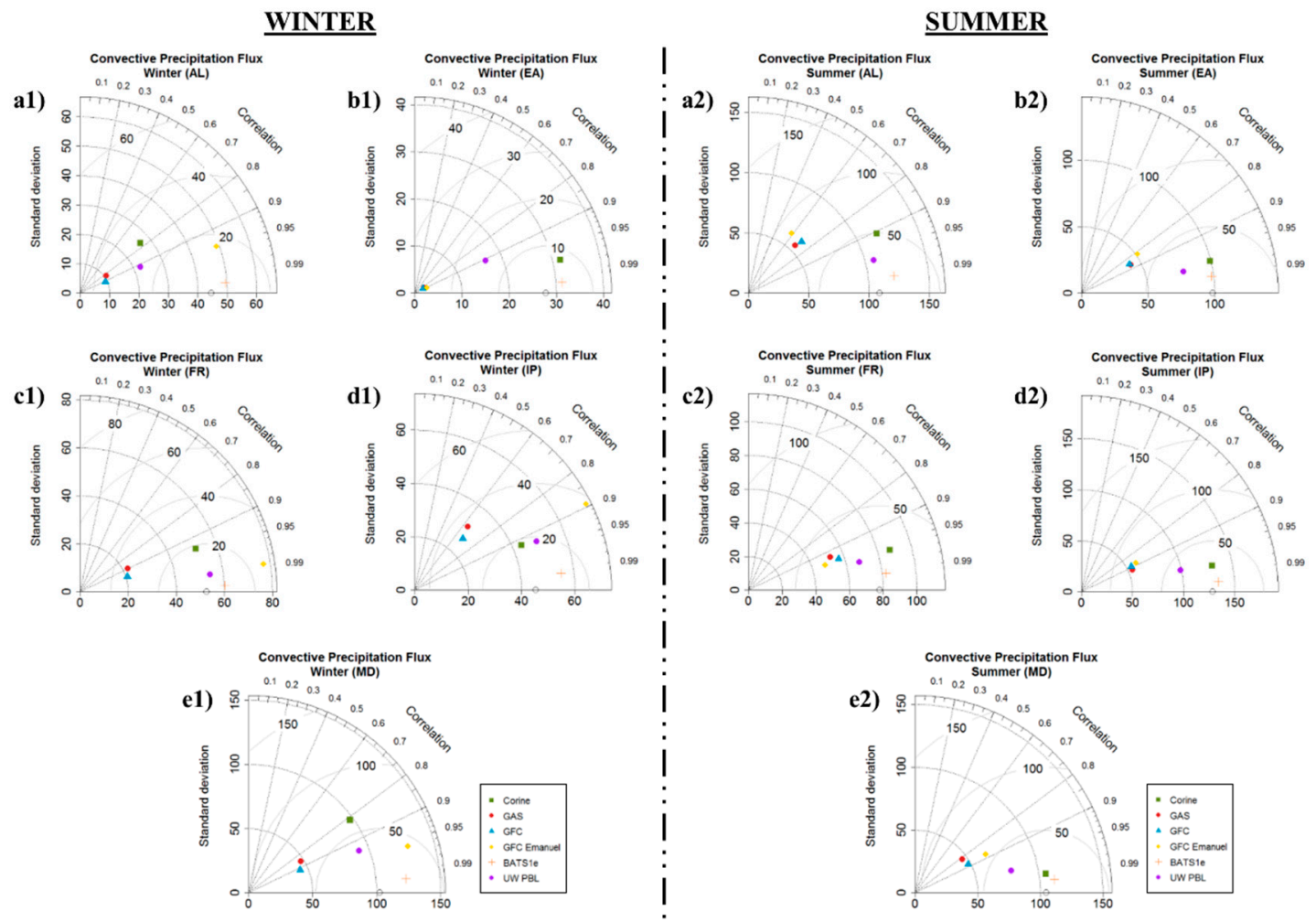

Figure 5. Taylor diagrams exploring the model's performance for convective precipitation over the five sub-regions $(a \rightarrow A L, b \rightarrow E A, c \rightarrow F R, d \rightarrow I P, e \rightarrow M D)$ during winter and summer. The markers in Taylor diagrams represent the different simulations. The default simulation is being used as reference field. 
During summer (Figure 6), in GAS and GFC run a significant decrease of total precipitation is detected in mainland (in convective precipitation also Mixed run presents a decrease), while a small but significant increase is observed in maritime areas in both cases. Total and convective precipitation do not present any significant changes in the case of BATS1e simulation, while in UW-PBL run a significant decrease is evident in continental areas. This decrease is more intense for total precipitation. CORINE simulation is characterized by a significant increase of the two parameters in Massif Central Mountains and the Iberian Peninsula. Regarding Taylor diagrams, BATS1e simulation presents again the most similar performance for both total (Figure 4) and convective (Figure 5) precipitation in all sub-regions. The decrease of the parameter in the case of GAS, GFC and Mixed simulations is also detected in Taylor diagrams.

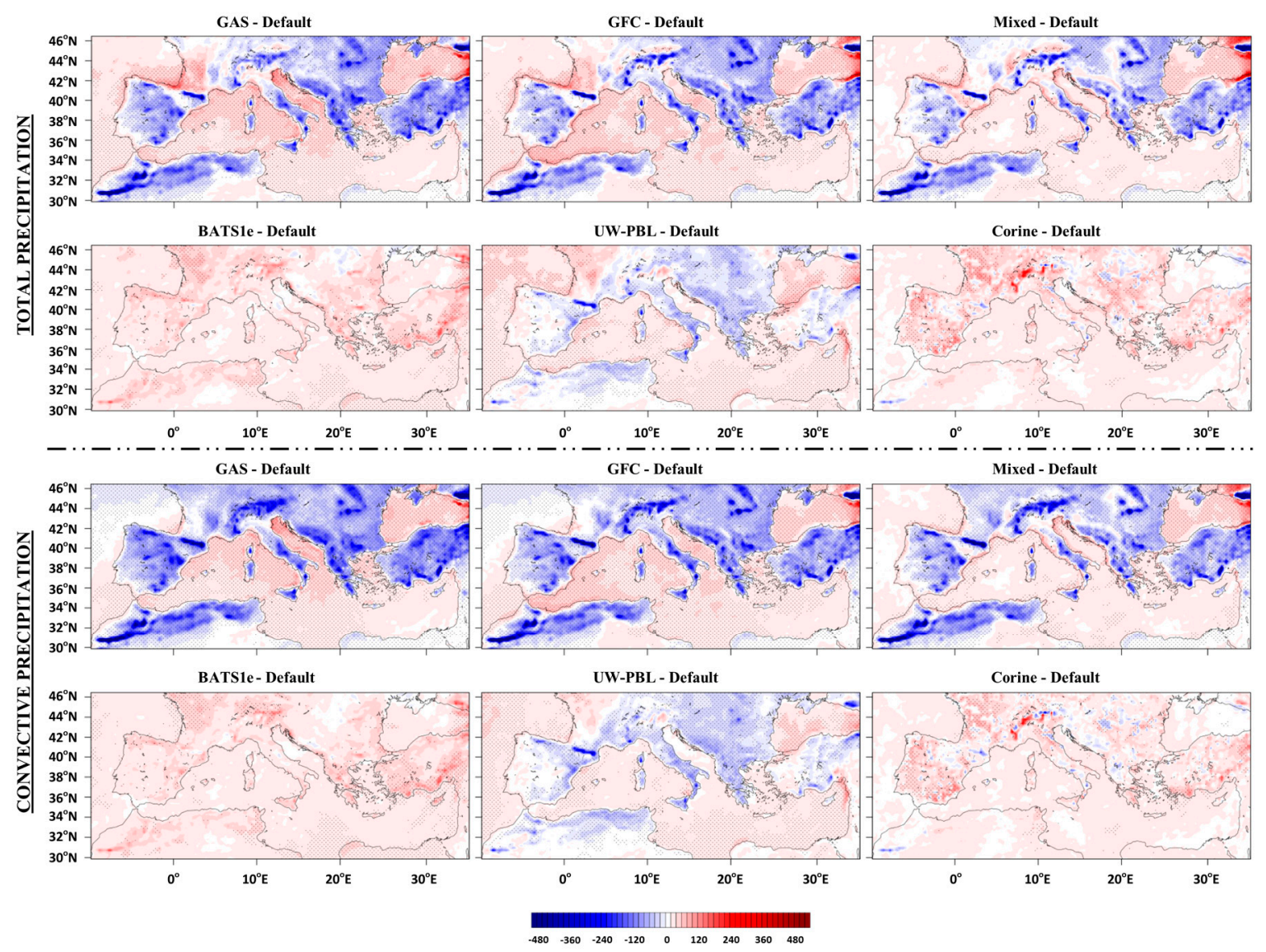

Figure 6. Differences in total and convective precipitation from the default simulation for the performed simulations during summer. The statistical significance of the differences in the maps is represented by the dotted areas.

\subsection{Near Surface $(2 \mathrm{~m})$ Temperature $\left({ }^{\circ} \mathrm{C}\right)$}

Subsequently, maximum and minimum temperature at $2 \mathrm{~m}$ are examined. During winter (Figure 7), the two parameters present similar results. More specifically, in GAS and GFC simulations a statistically significant decrease is observed in maritime areas and part of the westward continental areas and this decrease expands in Eastern Europe in the case of maximum temperature. There is no significant change in Mixed run except for central Iberian Peninsula, where maximum temperature presents a reduction. On the contrary, BATS1e simulation is characterized by a significant increase of the parameter. Maximum temperature in UW-PBL run decreases significantly in maritime areas, France, Italy and the Iberian Peninsula, while minimum temperature presents an increase in the Alps and Eastern Europe. Changes in land cover lead to a significant decrease of both parameters in coastal lines. In Taylor diagrams, all simulations are in a close agreement with the reference field for both minimum (Figure 8) and maximum (Figure 9) temperature, as the RMS difference is nearly zero, the 
standard deviation is similar to that of the reference field and the correlation coefficient is $>0.99$. BATS1e and Mixed simulation present almost the same performance in all sub-regions.

During summer (Figure 10) the results for minimum and maximum temperature are again similar, but the changes are more intense in maximum temperature. More specifically, changes in cumulus convection scheme (GAS and GFC) and planetary boundary layer scheme (UW-PBL) lead to a decrease of the two parameters, but in Mixed run the decrease is detected only in continental and part of maritime areas. Maximum temperature remains unmodified in BATS1e run, while minimum temperature is increasing significantly in part of Europe and maritime areas. Maximum temperature in CORINE simulation decreases in Massif Central Mountains and the Iberian Peninsula. The closest performance to the reference field is detected only in BATS1e for minimum (Figure 8) and maximum (Figure 9) temperature, according to Taylor diagrams.

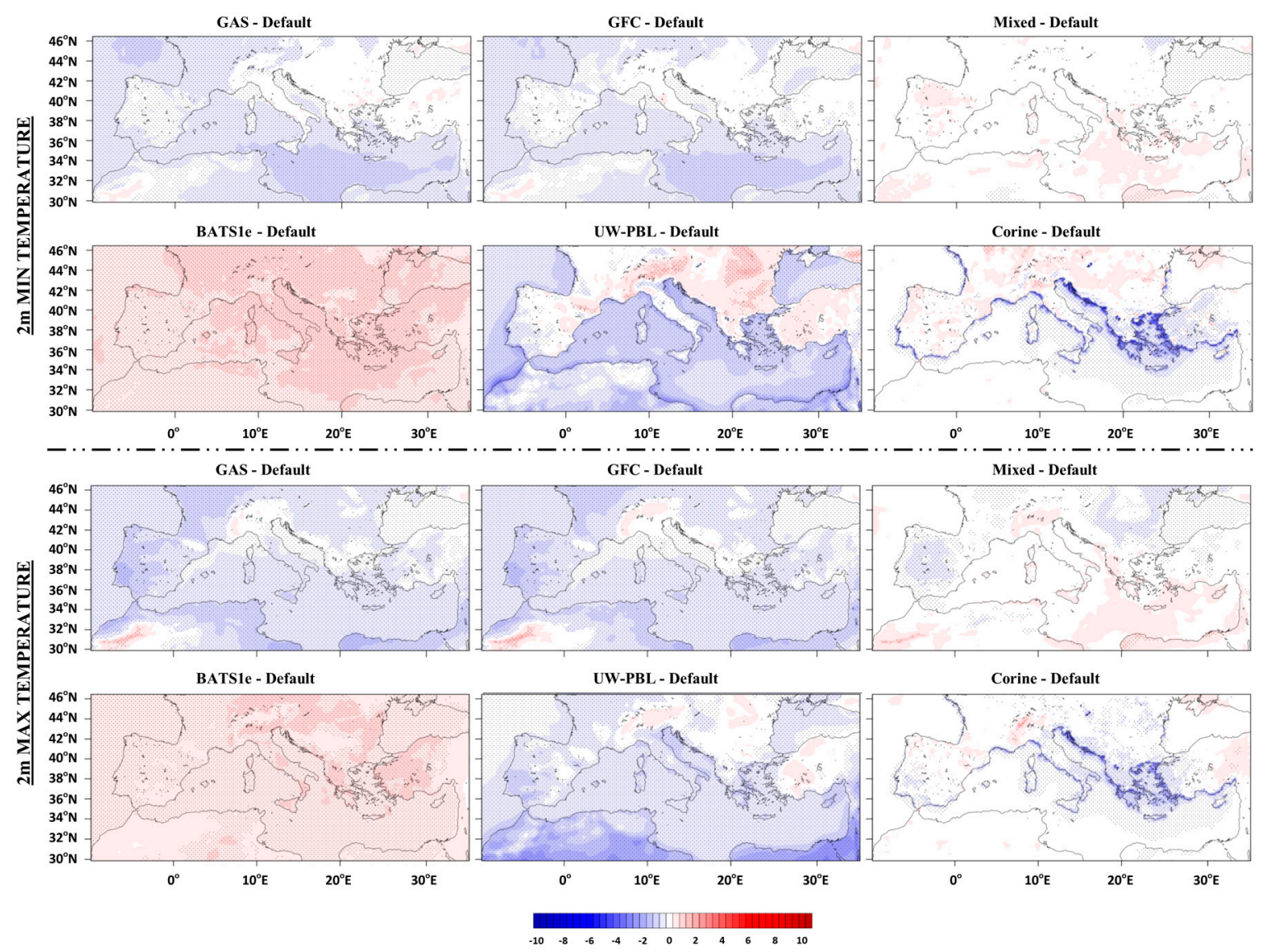

Figure 7. Differences in near surface $(2 \mathrm{~m}) \mathrm{min}$ and max temperature from the default simulation for the performed simulations during winter. The statistical significance of the differences in the maps is represented by the dotted areas. 

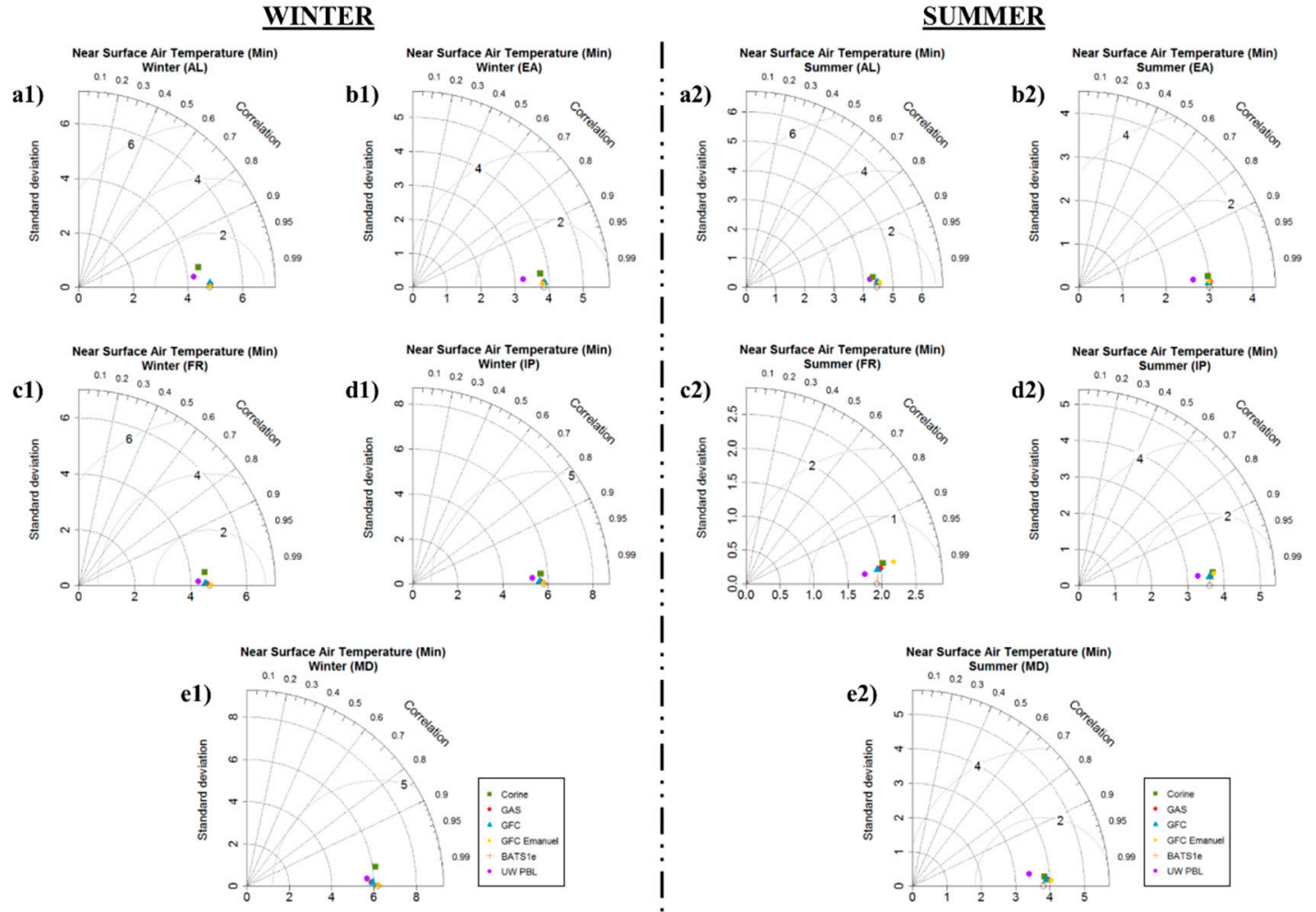

Figure 8. Taylor diagrams exploring the model's performance for near surface min temperature over the five sub-regions $(a \rightarrow A L, b \rightarrow E A, c \rightarrow F R, d \rightarrow I P, e \rightarrow M D)$ during winter and summer. The markers in Taylordiagramsrepresentthedifferentsimulations.Thedefaultsimulationisbeingusedasreferencefield.

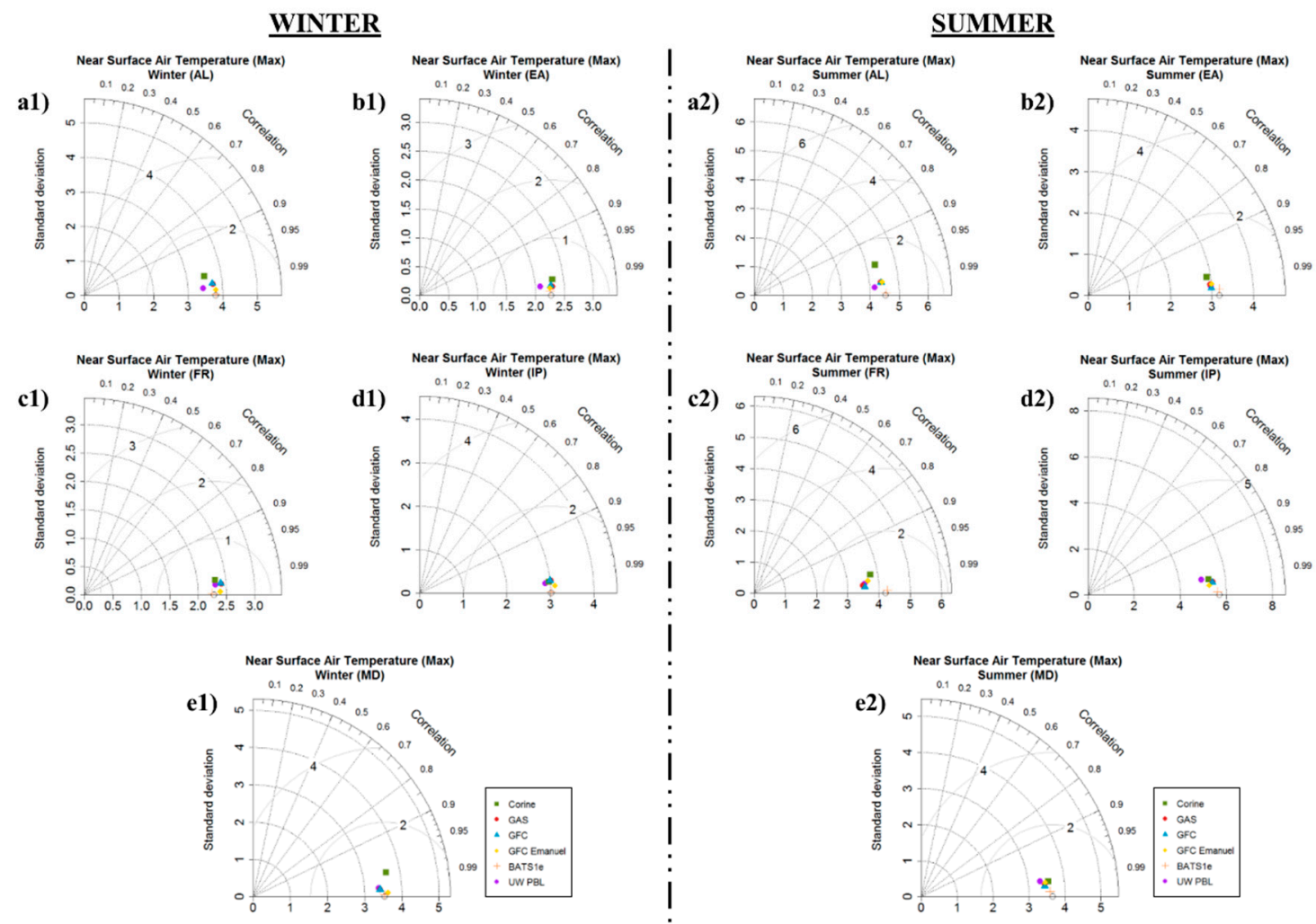

Figure 9. Taylor diagrams exploring the model's performance for near surface max temperature over the five sub-regions $(a \rightarrow A L, b \rightarrow E A, c \rightarrow F R, d \rightarrow I P, e \rightarrow M D)$ during winter and summer. The markers in Taylor diagrams represent the different simulations. The default simulation is being used as reference field. 

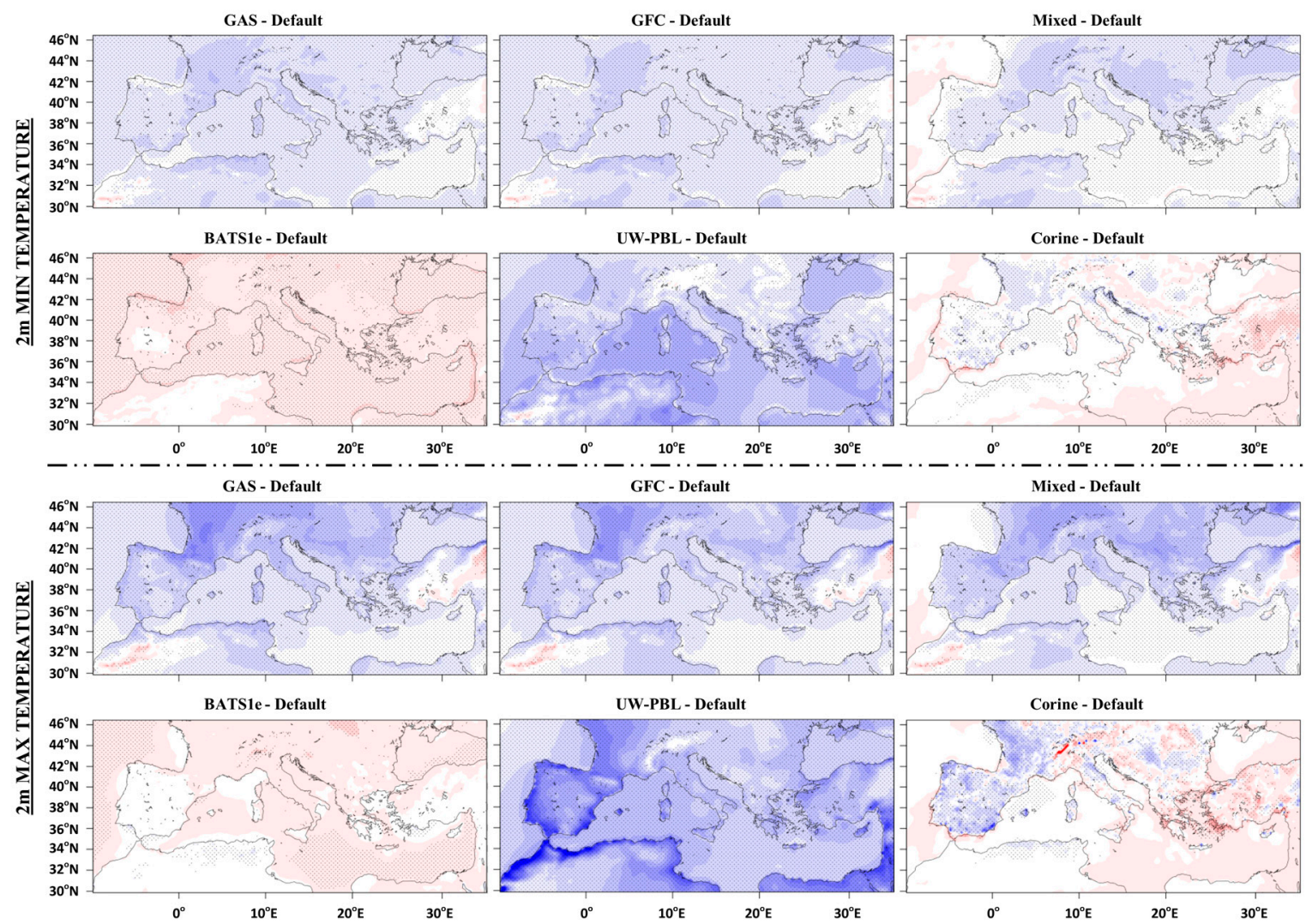

UW-PBL - Default
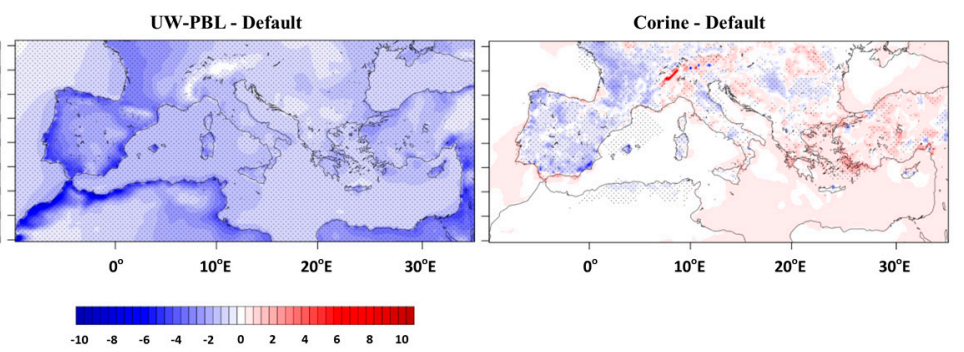

Figure 10. Differences in near surface $(2 \mathrm{~m}) \mathrm{min}$ and max temperature from the default simulation for the performed simulations during summer. The statistical significance of the differences in the maps is represented by the dotted areas.

\section{Conclusions}

The purpose of this research is to investigate the sensitivity of RegCM4 to the different physics parameterization schemes for the Mediterranean region in terms of precipitation and temperature. Seven ERA-Interim-driven simulations were performed with changes in the model's physics parameterization schemes. A division of the area of study into five sub-regions was performed according to the common EURO-CORDEX analysis domain, in order to thoroughly investigate the model's performance.

Regarding precipitation, the parameter was reduced in the majority of the area of study from changes in planetary boundary layer scheme (UW-PBL simulation), while BATS1e Monin-Obukhov scheme led to an increase of precipitation. Changes in cumulus convection scheme resulted to an increase of the parameter in continental areas, while maritime areas were characterized by a decrease of precipitation, which is in accordance to the findings of [5]. The results are quite the opposite during summer. Changes in land cover data resulted to a more detailed mapping of land cover in the area of study. Precipitation presented a decrease as it is directly affected by landuse. Finally, in the case of minimum and maximum temperature, a reduction of warm biases was detected in UW-PBL scheme. Similar are the findings of [6]. In contrast to MIT-Emanuel scheme, Grell scheme presents a cold bias, which is in agreement with the findings of [4]. BATS1e scheme appear to reduce the cold bias, which is consistent with [5] who found an increase of minimum and maximum temperature, while changes in land cover led to a reduction of temperature. This result adds to the findings of [28], who detected a decrease of temperature in China.

Acknowledgments: This research has been co-financed by the European Union (European Social Fund-ESF) and Greek national funds through the Operational Program "Education and Lifelong Learning" of the National Strategic Reference Framework (NSRF)-Research Funding Program: Thales. Investing in knowledge society 
through the European Social Fund (www.thalis-ccseawavs.web.auth.gr)/Results presented in this work have been produced using the AUTH Compute Infrastructure and Resources.

Author Contributions: Kondylia Velikou designed and performed the simulations, analyzed the data and wrote the paper. Konstantia Tolika supervised the research and assisted in the review process.

Conflicts of Interest: The authors declare no conflict of interest.

\section{References}

1. NASA Science: Climate Variability. Available online: https:/science.nasa.gov/earthscience/oceanography/ocean-earth-system/climate-variability (accessed on 25 June 2017).

2. Oke, T.R. Boundary Layer Climates, 2nd ed.; Routledge-Taylor \& Francis Group e-Library: Abingdon Oxford, UK, 2002; 435p.

3. The Environmental Literacy Council: Land Use Changes \& Climate. Available online: https://enviroliteracy.org/air-climate-weather/climate/land-use-changes-climate/ (accessed on 25 June 2017).

4. Zanis, P.; Douvis, C.; Kapsomenakis, I.; Kioutsioukis, I.; Melas, D.; Pal, J.S. A sensitivity study of the Regional Climate Model (RegCM3) to the convective scheme with emphasis in central eastern and southeastern Europe. Theor. Appl. Climatol. 2009, 97, 327-337, doi:10.1007/s00704-008-0075-8.

5. Martínez-Castro, D.; Porfirio da Rocha, R.; Bezanilla-Morlot, A.; Alvarez-Escudero, L.; Reyes-Fernández, J.P.; Silva-Vidal, Y.; Arritt, R.W. Sensitivity studies of the RegCM3 simulation of the summer precipitation, temperature and local wind field in the Caribbean Region. Theor. Appl. Climatol. 2006, 86, 5-22, doi:10.1007/s00704-005-0201-9.

6. Güttler, I.; Branković, Č.; O’Brien, T.A.; Coppola, E.; Grisogono, B.; Giorgi, F. Sensitivity of the regional climate model RegCM4.2 to planetary boundary layer parameterization. Clim. Dyn. 2014, 43, 1753-1772, doi:10.1007/s00382-013-2003-6.

7. Yan, Y.; Zheng-Hui, X. A simulation study on climatic effects of land cover change in China. Adv. Clim. Chang. Res. 2013, 4, 117-126, doi:10.3724/SP.J.1248.2013.117.

8. Giorgi, F.; Marinucci, M.R.; Bates, G.T. Development of a second generation regional climate model (RegCM2). Part I: Boundary layer and radiative transfer processes. Mon. Weather Rev. 1993, 121, 2794-2813, doi:10.1175/152-0493(1993)121<2794:DOASGR>2.0.CO;2.

9. Giorgi, F.; Marinucci, M.R.; Bates, G.T.; DeCanio, G. Development of a second generation regional climate model (RegCM2). Part II: Convective processes and assimilation of lateral boundary conditions. Mon. Weather Rev. 1993, 121, 2814-2832, doi:10.1175/1520-0493(1993)121<2814:DOASGR>2.0.CO;2.

10. Elguindi, N.; Bi, X.; Giorgi, F.; Nagarajan, B.; Pal, J.; Solmon, F.; Rauscher, S.; Zakey, A.; O’Brien, T.; Nogherotto, R.; et al. Regional Climate Model RegCM User Manual Version 4.4; International Centre for Theoretical Physics (ICTP): Trieste, Italy, 2014.

11. Grell, G.A.; Dudhia, J.; Stauffer, D.R. A Description of the Fifth-Generation Penn State/NCAR Mesoscale Model (MM5); NCAR Technical Note, NCAR/TN-398+STR; NCAR-UCAR (National Center for Atmospheric Research): Boulder, CO, USA, 1994; doi:10.5065/D60Z716B.

12. Kotlarski, S.; Keuler, K.; Christensen, O.B.; Colette, A.; Déqué, M.; Gobier, A.; Goergen, K.; Jacob, D.; Lüthi, D.; van Meijgaard, E.; et al. Regional climate modeling on European scales: A joint standard evaluation of the EURO-CORDEX RCM ensemble. Geosci. Model Dev. 2014, 7, 1297-1333, doi:10.5194/gmd-7-1297-2014.

13. Emanuel, K.A. A scheme for representing cumulus convection in large-scale models. J. Atmos. Sci. 1991, 48, 2313-2335, doi:10.1175/1520-0469(1991)048<2313:ASFRCC>2.0.CO;2.

14. Grell, G.A. Prognostic evaluation of assumptions used by cumulus parameterizations. Mon. Weather Rev. 1993, 121, 764-787, doi:10.1175/1520-0493(1993)121<0764:PEOAUB>2.0.CO;2.

15. Arakawa, A.; Schubert, W.H. Interaction of a cumulus cloud ensemble with large-scale environment, Part I. J. Atmos. Sci. 1974, 31, 674-701, doi:10.1175/1520-0469(1974)031<0674:IOACCE>2.0.CO;2.

16. Fritsch, J.M.; Chappell, C.F. Numerical prediction of convectively driven mesoscale pressure systems. Part I: Convective parameterization. J. Atmos. Sci. 1980, 37, 1722-1733, doi:10.1175/15200469(1980)037<1722:NPOCDM>2.0.CO;2.

17. Fritsch, J.M.; Chappell, C.F. Numerical prediction of convectively driven mesoscale pressure systems. Part II: Mesoscale model. J. Atmos. Sci. 1980, 37, 1734-1762, doi:10.1175/15200469(1980)037<1734:NPOCDM>2.0.CO;2. 
18. Holtslag, A.A.M.; de Bruijn, E.I.F.; Pan, H.L. A high resolution air mass transformation model for shortrange weather forecasting. Mon. Weather Rev. 1990, 118, 1561-1575, doi:10.1175/15200493(1990)118<1561:AHRAMT>2.0.CO;2.

19. Grenier, H.; Bretherton, C.S. A moist PBL parameterization for large-scale models and its application to subtropical cloud-topped marine boundary layers. Mon. Weather Rev. 2001, 129, 357-377, doi:10.1175/15200493(2001)129<0357:AMPPFL>2.0.CO;2.

20. O’Brien, T.A.; Chuang, P.Y.; Sloan L.C.; Faloona I.C.; Rossiter, D.L. Coupling a new turbulence parameterization to the RegCM adds realistic stratocumulus clouds. Geosci. Model Rev. 2012, 5, 989-1008, doi:10.5194/gmd-5-989-2012.

21. Zeng, X.; Zhao, M.; Dickinson, R.E. Intercomparison of bulk aerodynamic algorithms for the computation of sea surface fluxes using TOGA COARE and TAO data. J. Clim. 1998, 11, 2628-2644, doi:10.1175/15200442(1998)011<2628:IOBAAF>2.0.CO;2.

22. Heymann, Y.; Steemans, C.; Lenco, M.; Wyatt, B.; Weber, J.L.; O’Brien, C.; Cornaert, M.H.; Sifakis, N. CORINE Land Cover - Technical Guide; European Commission: Luxembourg, 1994; 136p.

23. Bossard, M.; Feranec, J.; Otahel, J. CORINE Land Cover Technical Guide-Addendum 2000; Technical Report No. 40; European Environment Agency (EEA): Copenhagen, Denmark, 2000; 105p.

24. Dickinson, R.E.; Henderson-Sellers, A.; Kennedy, P.J. Biosphere-Atmosphere Transfer Scheme (BATS) Version 1e as Coupled to the NCAR Community Climate Model; NCAR Technical Note, NCAR/TN-387+STR; NCARUCAR (National Center for Atmospheric Research): Boulder, CO, USA, 1993; doi:10.5065/D67W6959.

25. Giorgi, F.; Bi, X.; Qian, Y. Indirect vs. Direct effects of anthropogenic sulfate on the climate of East Asia as simulated with a regional coupled climate-chemistry/aerosol model. Clim. Chang. 2003, 58, 345-376, doi:10.1023/A:1023946010350.

26. Wilks, D.S. Statistical Methods in Atmospheric Sciences, 3rd ed.; Elsevier Academic Press: San Diego, CA, USA, 2011; 676p.

27. Taylor, K.E. Summarizing multiple aspects of model performance in a single diagram. J. Geophys. Res. 2001, 106, 2156-2202, doi:10.1029/2000JD900719.

28. Yan, Y.; Zheng-Hui X. A simulation study on climatic effects of land cover change in China. Adv. Clim. Chang. Res. 2013, 4, 117-126, doi:10.3724/SP.J.1248.2013.117

(C) 2017 by the authors. Licensee MDPI, Basel, Switzerland. This article is an open access article distributed under the terms and conditions of the Creative Commons Attribution (CC BY) license (http://creativecommons.org/licenses/by/4.0/). 